\title{
ARTIGO
}

do1 https://doi.org/10.22481/praxisedu.v16i42.6281

\section{A ARITMÉTICA NA SEÇÃO PARA PEQUENOS MATHEMÁTICOS DA REVISTA} O ECHO

\author{
THE ARITHMETIC IN THE SECTION FOR SMALL MATHEMATICIANS OF THE \\ ECHO MAGAZINE
}

ARITMÉTICA EN LA SECCIÓN PARA PEQUEÑOS MATEMÁTICOS DE LA REVISTA EL ECHO

Silvio Luiz Martins Britto
Universidade Luterana do Brasil - Brasil

Malcus Cassiano Kuhn

Instituto Federal de Educação, Ciência e Tecnologia Sul-rio-grandense - Brasil

Arno Bayer

Universidade Luterana do Brasil - Brasil

\begin{abstract}
Resumo: O tema deste artigo é a Matemática em revista veiculada por colégio jesuíta do Rio Grande do Sul, no século XX. O objetivo é analisar os conhecimentos aritméticos nos problemas recreativos da seção Para Pequenos Mathemáticos da revista O Echo. Como o tema se insere na História da Educação Matemática no estado gaúcho, este estudo qualitativo e documental se ampara na história cultural, para análise da revista editada pelo Colégio Anchieta de Porto Alegre, no século passado. O público-alvo do Echo era a comunidade escolar e a mocidade católica brasileira, pois não havia revistas para os jovens estudantes, com conteúdos religiosos e morais e de formação geral. Nos problemas recreativos analisados, observaram-se conhecimentos aritméticos relacionados com operações fundamentais, critérios de divisibilidade, progressões, permutações e arranjos simples, evidenciando-se o raciocínio lógico e charadas. Os editores buscavam despertar o interesse e a curiosidade da mocidade estudiosa, contribuindo para circulação da revista e formação da juventude católica nos colégios onde a mesma circulava.
\end{abstract}

Palavras chave: História da Educação. Jesuítas. Matemática.

\begin{abstract}
The theme of this article is the Mathematics in a magazine published by a Jesuit college in Rio Grande do Sul, in the $20^{\text {th }}$ century. The objective is to analyze the arithmetic knowledge in recreational problems in the section For Small Mathematicians of The Echo magazine. As the theme is inserted in the History of Mathematics Education in the gaucho state, this qualitative and documentary study is based on cultural history for analysis of the magazine, published by Anchieta College of Porto Alegre, in the last century. The target audience of the Echo was the school community and the Brazilian Catholic youth, as there were no magazines for the young students, with religious and moral
\end{abstract}


content and general formation. In the recreational problems analyzed, arithmetic knowledge related to fundamental operations, divisibility criteria, progressions, permutations and simple arrangements was observed, evidencing the logical reasoning and charades. The editors sought to arouse the interest and curiosity of studious youth, contributing to circulation of the magazine and formation of the Catholic youth in the schools where it circulated.

Keywords: History of Education. Jesuits. Mathematics.

Resumen: El tema de este artículo es Matemáticas en una revista publicada por un colegio jesuita en Rio Grande do Sul, en el siglo XX. El objetivo es analizar el conocimiento aritmético en problemas recreativos en la sección Para Pequeños Matemáticos de la revista $\mathrm{O}$ Echo. A medida que el tema se inserta en la Historia de la Educación Matemática en el estado gaucho, este estudio cualitativo y documental se basa en la historia cultural para análisis de la revista, publicada por Colegio Anchieta de Porto Alegre, en el siglo pasado. El público objetivo del Echo era la comunidad escolar y la juventud católica brasileña, ya que no había revistas para jóvenes estudiantes, con contenido religioso y moral y formación general. En los problemas recreativos analizados se observó conocimiento aritmético relacionado con operaciones fundamentales, criterios de divisibilidad, progresiones, permutaciones y arreglos simples, evidenciando el razonamiento lógico y las charadas. Los editores trataron de despertar el interés y la curiosidad de jóvenes estudiosos, contribuyendo a la circulación de la revista y la formación de la juventud católica en las escuelas donde circulaba.

Palabras clave: Historia de la Educación. Jesuitas. Matemática.

\section{Introdução}

Este artigo tem por objetivo analisar as edições da revista $O$ Echo, com ênfase para os conhecimentos de aritmética relacionados com os problemas recreativos da seção "Para Pequenos Mathemáticos" dessa revista. Trata-se de um estudo iniciado durante a elaboração da tese, "O ensino da aritmética nas escolas paroquiais católicas e no Ginásio Nossa Senhora da Conceição de São Leopoldo nos séculos XIX e XX sob a ótica dos Jesuítas” (BRITTO, 2016), e aprofundado no estágio Pós-doutoral no Programa de Pós-graduação em Ensino de Ciências e Matemática (PPGECIM), da Universidade Luterana do Brasil (ULBRA), tendo como questão norteadora a Matemática veiculada pelos Jesuítas em escolas católicas brasileiras no século XX.

Os trabalhos desenvolvidos pelas Ordens religiosas que chegaram ao Rio Grande do Sul (RS), após a segunda metade do século XIX, deixaram relevantes contribuições. Destacam-se os Jesuítas entre essas Ordens, por meio de trabalhos missionários, inicialmente, junto às colônias de imigrantes alemães católicos e, posteriormente, com a criação de uma rede de Ginásios e Seminários que contribuíram para a formação da juventude gaúcha. Dentre 
os educandários criados pela Ordem, destaca-se o Colégio Anchieta, com sede em Porto Alegre/RS.

A revista $O$ Echo foi editada pelo Colégio Anchieta, por meio da Typographia do Centro, localizada em Porto Alegre, no período de abril de 1914 a dezembro de 1931. A partir de 1932 , a revista passa a ser denominada $O E c o$, devido à reforma ortográfica ${ }^{1}$. O públicoalvo do Echo era a comunidade escolar e a mocidade católica brasileira, pois, segundo os editores, não havia revistas para os jovens estudantes. A revista apresentava cultura geral e valores católicos, por isso era uma revista destinada para os jovens católicos.

O estudo da Matemática em revistas do século passado é observado em trabalhos de Weiduschadt (2012), Kuhn (2015), Kuhn e Bayer (2017), Britto, Bayer e Kuhn (2020), entre outros. Como o tema desta investigação se insere na História da Educação Matemática no RS, este estudo qualitativo e documental, tem aporte metodológico na história cultural, a partir da perspectiva de Chartier (1990). Para investigar a revista $O$ Echo, visitas foram realizadas ao acervo particular do professor Luiz Osvaldo Leite ${ }^{2}$, em Porto Alegre, onde se encontram as edições dessa fonte histórica. Ao pesquisar cada edição, compilaram-se os 63 problemas recreativos da seção "Para Pequenos Mathemáticos" para posterior análise à luz do referencial teórico-metodológico.

No estudo dos problemas recreativos da seção "Para Pequenos Mathemáticos" da revista $O$ Echo, além do referencial teórico-metodológico, características da revista e uma abordagem de conhecimentos de aritmética relacionados com esses problemas são apresentados.

\section{A história cultural como aporte teórico-metodológico}

De acordo com Chartier (1990), uma questão desafiadora para a história cultural é o uso que as pessoas fazem dos objetos que lhes são distribuídos ou modelos que lhes são impostos, uma vez que há sempre uma prática diferenciada na apropriação dos objetos colocados em circulação. Nessa perspectiva, pode-se dizer que a imprensa pedagógica, aqui representada pela revista $O$ Echo, foi um veículo para circulação de ideias que traduziam

\footnotetext{
${ }^{1}$ Em 30 de abril de 1931, entraram em acordo a Academia Brasileira de Letras e a Academia das Ciências de Lisboa, no sentido de ser adotado um único sistema ortográfico no Brasil e em Portugal. Esse entendimento teve a aprovação oficial do Governo Provisório, por força do Decreto nº 28.128, de 15 de junho de 1931.

${ }^{2}$ Graduado em Filosofia e Teologia pela UNISINOS e UFRGS. Atuou na área de Filosofia, com ênfase em História da Filosofia, Ética e Psicologia. Foi diretor do Instituto de Psicologia da UFRGS e professor Emérito dessa Instituição, desde 2008. Foi aluno do Colégio Anchieta de 1944 a 1950 e atuou como professor nessa instituição, de 1956 a 1959 e de 1965 até a década de 1980.
} 
valores e comportamentos que se desejava ensinar - a prática religiosa católica, sendo postas em convergência com outras estratégias políticas e culturais no estado gaúcho.

Ainda conforme Chartier (1990), as noções complementares de práticas e representações são úteis para examinar os objetos culturais produzidos, os sujeitos produtores e receptores de cultura, os processos que envolvem a produção e a difusão cultural, os sistemas que dão suporte a estes processos e sujeitos e as normas a que se conformam as sociedades através da consolidação de seus costumes. Para a produção de uma revista, como $O$ Echo, foram movimentadas determinadas práticas culturais e também representações, sem contar que a própria revista, depois de produzida, difundia novas representações e contribuía para a produção de novas práticas.

Para Chartier (1990), as práticas culturais que aparecem na construção de uma revista são tanto de ordem autoral (modos de escrever, pensar ou expor o que será escrito), como editoriais (reunir o que foi escrito para constituí-la em revista), ou ainda artesanais (a construção da revista na sua materialidade). Da mesma forma, quando um redator se põe a escrever uma revista, ele se conforma a determinadas representações do que deve ser uma revista, a certas representações concernentes aos temas por ele desenvolvidos. Este redator também poderá se tornar criador de novas representações, que encontrarão no devido tempo uma ressonância maior ou menor no circuito do leitor ou na sociedade mais ampla. A leitura de uma revista também gera práticas criadoras, podendo produzir concomitantemente práticas sociais. Essa leitura poderá ser individual ou coletiva, e o seu conteúdo poderá ser imposto ou rediscutido. A partir da leitura e difusão da revista, poderão ser geradas inúmeras representações novas sobre os temas que a atravessam, que em alguns casos poderão passar a fazer parte das representações coletivas. De acordo com Chartier (1990, p. 17), a história cultural tem por principal objeto identificar o modo como "em diferentes lugares e momentos uma determinada realidade cultural é construída, pensada, dada a ler, por diferentes grupos sociais", o que está fortemente relacionado à noção de representação.

Serra (2010) complementa que o trabalho com revistas educacionais, na perspectiva da história cultural:

Possibilita a reconstrução histórica das práticas específicas desenvolvidas pelos autores, como também permite redesenhar os leitores visados por tais práticas, portanto a importância do estudo dos periódicos na sua materialidade. A partir do próprio impresso é possível recompor os projetos específicos como estratégias que visam a públicos leitores característicos. (SERRA, 2010, p. 25). 
Conforme Valente (2007), pensar os saberes escolares como elementos da cultura escolar e realizar o estudo histórico da matemática escolar exige que se devam considerar os produtos dessa cultura no ensino de Matemática, que deixaram traços que permitem o seu estudo, como a revista $O$ Echo, principal fonte documental desta investigação.

\section{A revista $O \mathrm{ECHO}$}

Desde que retornaram ao RS, em 1842, os Jesuítas concentraram suas atividades missionárias no processo de instrução do povo gaúcho, em particular nas colônias de imigrantes alemães. No ano de 1890, surge o Colégio Anchieta de Porto Alegre. Mantido e dirigido pelos padres da Companhia de Jesus, foi fundado como um simples colégio. No princípio, com a denominação de Colégio dos Padres $^{3}$, era destinado somente a meninos, sendo dividido em duas seções: alemã e brasileira. A preocupação máxima não era com a alfabetização, mas com a orientação moral e religiosa de seus alunos. (O ECO, 1965).

Em 1914, o Anchieta, como é conhecido, passa a editar a revista $O$ Echo, destinada à mocidade brasileira, abordando temas pertinentes em suas diferentes épocas de circulação. Sua publicação aconteceu pela Typographia do Centro, localizada em Porto Alegre, no período de abril de 1914 a dezembro de 1931. A partir de 1932, a revista passa a ser denominada $O E c o$, devido à reforma ortográfica. Segundo Leite (2018), a designação do nome da revista $O$ Echo se dá:

No sentido de que os ensinamentos ressoassem fortemente, produzissem eco nos jovens, nas famílias, em toda a população católica. Para os seus precursores, todos de origem alemã, essa deveria ter o mesmo efeito do eco produzido nos Alpes da Europa, onde em sua maioria tiveram sua infância. Nesses locais, os pastores caminhavam pelas montanhas e ao chamarem seus animais produziam sons, através de instrumentos que ecoavam por toda a região, sendo algo típico que a população costumava a ouvir. (LEITE, 2018, informação verbal ${ }^{4}$ ).

A revista Echo tinha circulação mensal, destinada à comunidade escolar, principalmente à mocidade estudiosa, conforme inscrição na capa das revistas publicadas, reunindo diversos temas. De acordo com Leite (2018), o corpo de redatores era constituído por um diretor e colaboradores, voluntários, que enviavam artigos para as edições da revista $\mathrm{O}$

\footnotetext{
${ }^{3}$ Em 1897, o Colégio muda de nome passando a se chamar São José. A denominação que o faria entrar para história do RS, como Colégio Anchieta, aconteceu em 1901, em homenagem ao Padre José de Anchieta, um fiel intérprete e seguidor da espiritualidade de Santo Inácio de Loyola, fundador da Congregação dos Jesuítas.

${ }^{4}$ Entrevista concedida por Luiz Osvaldo Leite, em Porto Alegre/RS, no dia 16 de março de 2018.
} 
Echo. Na Figura 1, apresentam-se capas da revista investigada em diferentes períodos, inicialmente com a denominação $O$ Echo, até dezembro de 1931, e depois a denominação $O$ Eco.

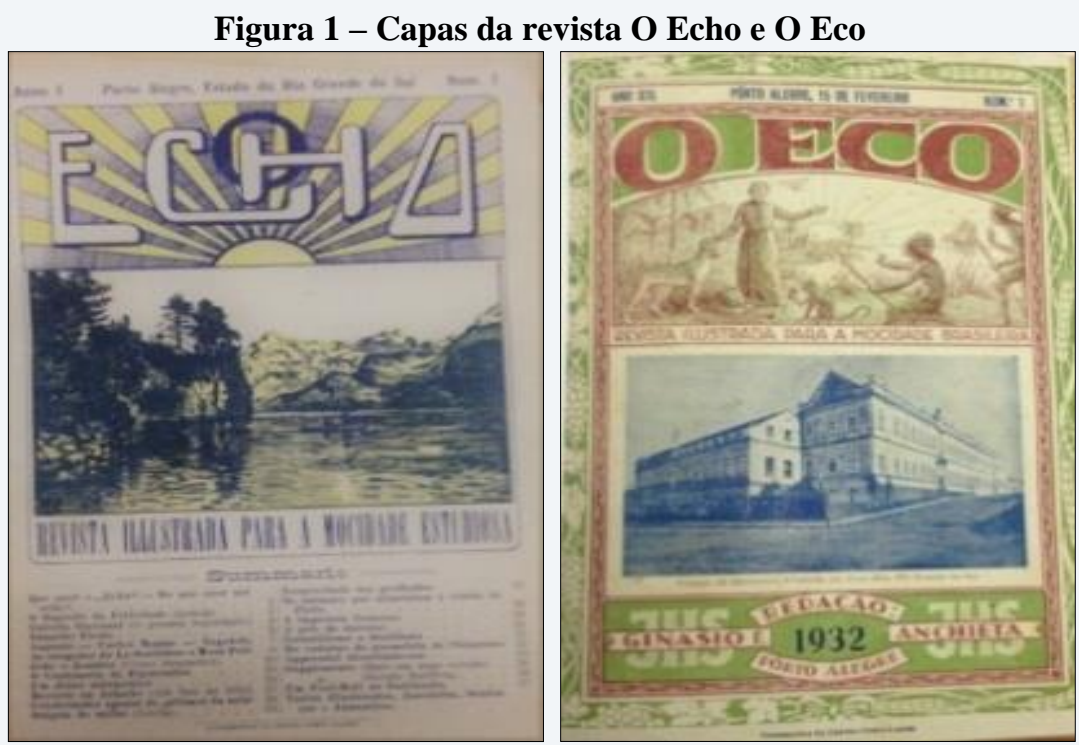

Fonte: O Echo, 1914; O Eco, 1932

Nas duas primeiras décadas, a capa da revista apresentou poucas alterações. Já nos anos seguintes, verificaram-se alterações com certa frequência, apresentando, por exemplo, imagem de colégios pelo país (objetivando buscar novos assinantes), personagens da história do Brasil, esportes, profissões, pontos turísticos do Brasil, entre outros. O objetivo da revista era:

Há um número de revistas de diversas espécies: revistas para todos sem distincção de classe, e revistas especiaes para as diversas classes de pessoas. Há revistas jurídicas, há revistas médicas, há revistas commerciaes e industriaes, há revistas marítimas e militares, há revistas eclesiásticas, até para a infância há não sei quantas revistas infantis. Só a mocidade não tem uma revista própria, uma revista feita especialmente para ella. É uma lacuna por demais sensível e que urge preencher. Pois, essa classe poderosa em número, essa classe a que se dá tal importância que é chamada esperança da pátria, será admissível que careça de uma vantagem de que gozam os outros? Eis a origem do "Echo": nasceu da necessidade evidente de ter também a mocidade uma revista própria, exclusivamente sua. (O ECHO, 1915, p. 1) $)^{5}$.

Editada, inicialmente, a cada vinte e cinco dias, com o primeiro número em fevereiro e o último em novembro de cada ano, a revista totalizava 12 edições por ano. Uma das revistas, normalmente a última do ano, abrangia dois números, já que em janeiro ela não era editada em virtude das férias escolares. A $1^{\text {a }}$ edição foi registrada em abril de 1914:

\footnotetext{
${ }^{5} \mathrm{Na}$ citação se mantém a ortografia da fonte original.
} 
Sahiu á luz o $1^{\circ}$ número do $\mathrm{O}$ Echo, revista mensal illustrada, na qual além de muitos colaboradores competentes que, em suas columnas, se dedicaram aos interesses da mocidade estudiosa do Brasil, os próprios alunos debaixo da direção de seus mestres, se estréam no manejo da pena. No suplemento "Echos dos Collegios" trocam os jovens escriptores impressões e notícias que particularmente affectam a vida internas dos collegios. (RELATÓRIO DO COLÉGIO ANCHIETA, 1914, p. 28, grifo do autor).

Cada edição era a continuação da anterior, inclusive na paginação, sendo que durante o ano eram publicadas de 350 a 430 páginas. $\mathrm{O}$ ano representava um volume, destacado em números romanos, e o mês representava um número natural. Os diferentes exemplares traziam artigos escritos e muitas gravuras, sendo sua estruturação semelhante em todas as edições. Nos 40 primeiros anos, a edição tinha um formato de $16 \mathrm{~cm}$ x 24 cm. Já em 1963, a revista ficou maior, com formato $32 \mathrm{~cm}$ x $23 \mathrm{~cm}$, passando a ter circulação bimestral.

Nos artigos escritos na revista Echo são apresentados poemas, notícias, reflexões de padres e professores, conferências, variedades, anedotas, contos, publicações de premiações de alunos por redação ou por competição esportiva, anúncios de propagandas, ciências, invenções, artes, matemática, astronomia, reforma da língua portuguesa, descobertas, sendo que, após 1950, começam a aparecer artigos direcionados à prática esportiva, como futebol, bola ao cesto, entre outros. Nesses artigos, também há ilustrações, como fotografias de colégios, imagens de papas, padres, alunos, ex-alunos, personagens da história do Brasil, santos da Igreja Católica, paisagens, ilustrações de textos, cenários de guerra, futebol e humor.

Para este artigo, foram examinados todos os exemplares da revista $\mathrm{O}$ Echo, desde sua primeira publicação em abril de 1914 até dezembro de 1931, totalizando 216 edições mensais. Destacaram-se os problemas recreativos da seção "Para Pequenos Mathemáticos", conforme abordagem apresentada na sequência.

\section{Problemas recreativos na seção "Para Pequenos Mathemáticos" da revista $O$ Echo}

Há 100 anos, na quarta edição da revista $O$ Echo de 1919, surge à seção "Para Pequenos Mathemáticos”6. Em sua apresentação, encontra-se:

\footnotetext{
${ }^{6}$ Nos anos em que a revista editou a seção "Para Pequenos Matemáticos" os editores responsáveis foram: o Pe. Germano Middeldorf S.J (1919 - 1922) e o Pe. Luiz Gonzaga Jaeger S.J (1924). Para maiores esclarecimentos sobre a vida e obras dos referidos editores, consultar Spohr (2011, p. 297-299 e p. 437-438).
} 
Reparastes no cabeçalho que hoje apparece no alto desta página? É novo para "O Echo", que pelo visto quer offerecer mais uma novidade aos seus bons amigos. Bem adivinhado! Mas reparae melhor: o cabeçalho só diz "Para pequenos mathemáticos". Por isso, se sois grandes virae a folha! Prosegui, que "O Echo" contem muito para vós. Isto que aqui vae é para pequenos - ou quiçá para grandes que felizmente ainda têm comprehensão para divertimentos e travessuras da infância buliçosa, alegre e feliz. (O ECHO, 1919, v. 4, p. 150, grifo do autor).

Nos volumes 4 a 10 de 1919, da referida revista, na seção "Para Pequenos Mathemáticos", é contada a história de um menino travesso, mas esperto, chamado de Chiquinho Mathemático. Essa história envolve o conhecimento matemático num contexto de vivência de crianças, intitulada "Chiquinho Mathemático e os noves-fora". No colégio, Chiquinho era conhecido como pequeno mathemático, devido a sua esperteza. Invenções e contas era seu lado forte. Todavia, seu lado fraco eram a gula e o egoísmo. Juntamente com seus três irmãos mais novos, Rudi, Norberto e Ricardo, seus dois primos, Antoninho e Victor, e um menino pobre da vizinhança, chamado Carlinhos, fundaram uma sociedade infantil denominada de "Sociedade Anti-arteirítica", cuja sede era a casa de Chiquinho Mathemático. Tal sociedade era presidida pelo próprio Chiquinho, sendo sua mãe a conselheira e o tio, o tesoureiro da mesma.

Conforme a história "Chiquinho Mathemático e os noves-fora", pelo dia de Natal, Chiquinho recebeu da madrinha uma cestinha com frutas: 7 figos, 8 maçãs, 5 marmelos, 5 pêssegos e 5 ameixas. Com fim educativo, a madrinha deixou escrito, num cartão de Natal, que ele não fosse egoísta e guloso e dividisse a metade das frutas entre seus irmãos. Como era um total de 30 frutas, deveria repartir 15 entre seus 3 irmãos. Chiquinho gostava de figos e maçãs, cuja quantidade somava 15 frutas, logo pensou em destinar a outra metade (marmelos, pêssegos e ameixas) para seus irmãos. Mas, a mensagem do cartão de Natal dizia que o menino deveria fazer a partilha das frutas, sem ser egoísta. Então, "Chiquinho Guloso" iria consultar o "Chiquinho Mathemático"? Pois bem, Chiquinho dispõe as frutas em fila comprida sobre uma mesa, aparentemente sem plano e ordem. Então, pediu que cada irmão tirasse 5 frutas a sorte e ele ficaria com o restante. Mas, essa retirada deveria acontecer por meio de uma espécie de jogo, ou seja, o jogo da sorte pelos noves-fora. Pede ao irmão mais novo que conte sempre até 9 e retire as frutas que corresponderem ao 9, até juntar 5 frutas. O mesmo deveria ser feito pelo irmão seguinte, continuando a contagem por onde parou o irmão precedente. E assim, o fizeram os 3 irmãos, pelo método dos noves-fora inventado por Chiquinho, sobrando sobre a mesa somente figos e maçãs, num total de 15 frutas. (Adaptado de O ECHO, v. 4 e v. 5, 1919). 
O intrigante nessa história é como Chiquinho fez a distribuição das frutas sobre a mesa, para que sobrassem somente suas frutas preferidas, os 7 figos e as 8 maçãs, após os irmãos terem feito as retiradas sucessivas das frutas, seguindo o jogo dos noves-fora, proposto pelo "pequeno mathemático". Ao dispor as 30 frutas em fila sobre a mesa, Chiquinho colocou as frutas desejadas em posições que não resultariam em noves-fora pela sua invenção. No Quadro 1, mostram-se as posições das frutas retiradas por cada irmão, de acordo com a invenção dos noves-fora:

Quadro 1 - Posições das frutas retiradas por cada irmão de Chiquinho

\begin{tabular}{|c|c|c|}
\hline Irmão & Posições das frutas e retiradas & Sequência de frutas retiradas \\
\hline mais novo & $\begin{array}{l}1,2,3,4,5, \underline{6}_{\left(4^{\circ}\right)}, 7,8, \underline{9}_{\left(1^{\circ}\right)}, 10,11,12,13,14,15, \\
\underline{16}_{\left(5^{\circ}\right)}, 17, \underline{18} \underline{(2}_{\left(2^{\circ}\right)}, 19,20,21,22,23,24,25,26, \\
\underline{(3}_{\left(3^{\circ}\right)}, 28,29,30 .\end{array}$ & $9,18,27,6$ e 16. \\
\hline do meio & $\begin{array}{l}1,2,3,4,5, \underline{7}_{\left(2^{\circ}\right)}, 8,10,11,12_{\left(5^{\circ}\right)}, 13,14,15,17, \\
19_{\left(3^{\circ}\right)}, 20,21,22,23,24,25,26_{\left(1^{\circ}\right)}, 28,29,30_{\left(4^{\circ}\right) .}\end{array}$ & $26,7,19,30$ e 12 . \\
\hline mais velho & $\begin{array}{l}1,2,3,4, \underline{5}_{\left(4^{\circ}\right)}, \underline{8}_{\left(2^{\circ}\right)}, 10,11,13,14,15,17,20,21, \\
\left.\underline{22}_{\left(3^{\circ}\right)}, \underline{23}_{\left(5^{\circ}\right)}, \underline{24}_{\left(1^{\circ}\right)}\right), 25,28,29 .\end{array}$ & $24,8,22,5$ e 23. \\
\hline
\end{tabular}

Fonte: Os autores do artigo.

Considerando o Quadro 1, conclui-se que Chiquinho, utilizando-se de conhecimentos matemáticos, colocou os figos e as maçãs nas posições 1, 2, 3, 4, 10, 11, 13, 14, 15, 17, 20, 21 25, 28 e 29, que não resultavam em noves-fora, para ficar com as 15 frutas preferidas.

De acordo com o volume 5 de $O$ Echo (1919), a revista era para a mocidade estudiosa se ocupar depois de feitas as lições escolares, aos domingos e nas tardes livres, especialmente em dias chuvosos, uma vez que em dias ensolarados tinham brincadeiras ao ar livre. Assim, os sete "pequenos mathemáticos" se reuniam na sede da "Sociedade Anti-arteirítica" para resolver os chamados "problemas recreativos". A maioria desses problemas era apresentada por meio de histórias envolvendo os "pequenos mathemáticos", geralmente, propostos por Chiquinho Mathemático aos demais membros da sociedade que são: Carlinhos, Ricardo, Norberto, Rudi, Antoninho e Victor, sendo que em todos os dias de chuva a sociedade estava em ação. Considerando o aporte teórico-metodológico deste artigo, a ideia dos editores da revista era associar abstrações matemáticas a coisas que faziam sentido à criança, aliando conceitos matemáticos a conhecimentos oriundos da experiência infantil.

A partir das edições de 1920 da revista $O$ Echo, na seção "Para Pequenos Mathemáticos", são apresentados 63 problemas recreativos e suas possíveis soluções em edições posteriores. O Quadro 2 mostra uma possível classificação dos problemas recreativos, considerando-se as principais áreas de Matemática: 
Quadro 2 - Classificação dos problemas recreativos

\begin{tabular}{|c|c|}
\hline Área & Quantitativo de problemas recreativos \\
\hline Álgebra & 14 \\
\hline Aritmética & 19 \\
\hline Geometria & 14 \\
\hline $\begin{array}{c}\text { Outros (problemas sem relação direta } \\
\text { com a Matemática) }\end{array}$ & 16 \\
\hline Total de problemas recreativos & 63 \\
\hline
\end{tabular}

Fonte: Os autores do artigo.

De acordo com a classificação realizada, observou-se uma distribuição uniforme dos problemas recreativos nas áreas da álgebra e da geometria, um predomínio de problemas envolvendo aritmética, havendo também problemas sem relação direta com a Matemática, servindo apenas como momentos de recreação. Nesse artigo se apresenta uma análise mais aprofundada de problemas recreativos com conteúdo de aritmética, como se pode observar a partir do problema descrito no Quadro 3 a seguir:

Quadro 3 - Problema aritmético

\begin{tabular}{|cc|}
\hline Victor, risque-me daí 6 algarismos de sorte que a soma do resto perfaça 20. \\
111 & -11 \\
777 & -- \\
$\underline{999}$ & $\frac{--9}{20}$ \\
\hline
\end{tabular}

Fonte: O Echo, 1920, v. 1, p. 30.

O problema recreativo descrito no Quadro 3 desafia um dos membros da "Sociedade Anti-Arteirítica" a obter a referida soma. Logo, a sua solução consiste em excluir o algarismo 1 , que corresponde à centena simples na primeira parcela, os três 7 , correspondentes à segunda parcela e, finalmente, dois algarismos 9, correspondentes à centena e dezena simples da última parcela. Somando-se os algarismos restantes, obtém-se a solução procurada.

No Quadro 4 se apresenta um problema recreativo que envolve raciocínio lógico de modo curioso.

\section{Quadro 4 - Problema de charada aritmética}

Tenho o número 666. Sem fazer operações aritméticas de espécie alguma o número tornou-se $1 \frac{1}{2}$ vezes maior.

Fonte: O Echo, 1920, v. 1, p. 30.

Para resolver essa charada, de forma mecânica, inverte-se o papel em que se escreveu o número 666. O resultado obtido será o número 999, que é igual a 11⁄2 x 666.

No excerto mostrado no Quadro 5, observa-se outro resultado numérico interessante envolvendo a soma dos nove algarismos do sistema decimal. Num primeiro momento, iniciando por 9 e, a seguir, por 1. Somando-se todos esses números, obtém-se o 45. 
Quadro 5 - Problema da subtração curiosa

Querem ver mais uma proeza da matemática? Tenho 45; subtraio 45 e ficam-me ainda 45.

$$
\begin{aligned}
& \text { Tenho } \Rightarrow \quad 987654321=45 \text { (Somando) } \\
& \text { Invertido dá } \Rightarrow-123456789=45 \text { (Somando) } \\
& \text { Subtraindo fica } \Rightarrow \overline{864195732=45} \text { (Somando) } \\
& \text { Logo: } 45-45=45
\end{aligned}
$$

Fonte: O Echo, 1920, v. 2, p. 79.

A curiosidade consiste em subtrair os números obtidos quando descritos em ordem decrescente (minuendo) pelo descrito em ordem crescente (subtraendo). O resultado dessas subtrações consiste nos nove algarismos do sistema decimal, e, ao somá-los, o resultado igualmente será 45 .

Já o problema descrito no Quadro 6 trás uma divisão curiosa relacionado o número de cavalos com vagões para transportá-los e os procedimentos adotados pelo soldado quanto ao número de vagões a serem utilizados.

\section{Quadro 6 - Problema da divisão dos vagões e dos cavalos}

Nem todos os soldados são pequenos mathemáticos. Como prova um fato da última guerra. Um soldado russo foi mandado requerer cavalos para o serviço do exército. Há muito custo reuniu 36 que era preciso transportar de trem para muito longe. Vai o soldado à estação e lá houve esse diálogo:

Soldado: Senhor chefe, para amanhã necessito de vagões para transportar cavalos.

Chefe: De quantos precisa?

Soldado: Quantos cavalos podem alojar num?

Chefe: 6.

Soldado: Então, com licença um instante. Nisso o soldado tira o seu caderno de notas e rabisca a conta: $36 \div 6$.

Fez a divisão e logo comunicou ao chefe o resultado singular: Senhor chefe, 51 carros.

Chefe: 51? Parece incrível! Para tantos parece que não há cavalos em todo o distrito. Por força houve engano na conta; 51 carros?!

Soldado: Nenhum mais, nenhum menos! Então o filho de meu pai não saberá fazer uma simples divisão?! Vamos à prova!

E o soldado tornou a fazer a divisão:

$36 \div 6=51$ fez a prova $51 \times 6=36$.

Quanto a mim, não quero saber quantos, até dos pequenos mathemáticos fazem às vezes contas de russo; só queria que me descobrissem os dois disparates da conta do russo.

Fonte: O Echo, 1920, v. 3, p. 116.

Em duas edições posteriores se apresenta a operação realizada pelo soldado e sua solução. Além disso, como ele realizou a prova validando o resultado obtido, exemplificado na Figura 2: 
Figura 2 - Solução do problema do Quadro 6

\begin{tabular}{|c|c|}
\hline $\begin{array}{l}36: 6=51 \\
\frac{30}{6} \\
\frac{-6}{0}\end{array}$ & $\begin{array}{l}51 \times 6= \\
6 \times 5=30 \\
6 \times 1=\frac{6}{36}\end{array}$ \\
\hline
\end{tabular}

Fonte: O Echo, 1920, v. 5, p. 197.

No Quadro 7 se apresenta um problema recreativo que envolve linguiças e os pesos utilizados, além de suas possíveis combinações para pesagem da mercadoria:

\section{Quadro 7 - Problema dos pesos do tio Pafuncio}

O tio Pafuncio, lidando com linguiças na balança, teve a boa ou má sorte de deixar cair um de seus pesos de pedra de 40 quilos. O peso se partira em 4 pedaços. Por pouco que o tio não cuspiu cobras e lagartas contra si mesmo e mais contra o peso partido. Examinando, porém, os 4 pedaços, não pode deixar de exclamar: "Ora, que fortuna no caiporismo! Já posso dispensar os outros pesos miúdos, com só esses 4 pedaços peso todos os quilos de 1 a 40. Sempre vale o ditado: Há males que vem por bem". Perguntas: Quem me diz quanto pesa cada pedaço? E como o tio Pafuncio arranja com os 4 os 40 pesos diferentes?

$$
\text { Fonte: O Echo, 1920, v. 6, p. } 230 .
$$

Inicialmente, constatou-se que os cacos do peso do tio Pafuncio, que se partiu, pesam 1, 3, 9 e 27 quilos, pois $1+3+9+27=40$ quilos. Trata-se de uma progressão geométrica (P.G.) de quatro termos em que o primeiro termo é 1, a razão é igual a 3 e a soma desses quatro termos é 40. A descoberta do tio Pafuncio permitiu dispensar os demais pesos menores, visto que ao combinar os cacos, podem-se obter todos os pesos de 1 a 40. O Quadro 8 revela todas as 40 combinações, utilizando somente os cacos com seus respectivos pesos.

Quadro 8 - Possibilidades utilizando os cacos de pesos

\begin{tabular}{|c|c|c|c|}
\hline \multicolumn{4}{|c|}{ Pesos dos 4 cacos: $1,3,9$ e $27 \mathrm{~kg}$} \\
\hline $1=1$ & $11=(9+3)-1$ & $21=27-9+3$ & $31=27+3+1$ \\
\hline $2=3-1$ & $12=9+3$ & $22=27-(9-3)$ & $32=27+9-(3+1)$ \\
\hline $3=3$ & $13=9+3+1$ & $23=27-(3+1)$ & $33=27+9-3$ \\
\hline $4=3+1$ & $14=27-(9+3+1)$ & $24=27-3$ & $34=27+9-(3-1)$ \\
\hline $5=9-(3+1)$ & $15=27-(9+3)$ & $25=27-3+1$ & $35=27+9-1$ \\
\hline $6=9-3$ & $16=27-(9+3)+1$ & $26=27-1$ & $36=27+9$ \\
\hline $7=(9+1)-3$ & $17=27-(9+1)$ & $27=27$ & $37=27+9+1$ \\
\hline $8=9-1$ & $18=27-9$ & $28=27+1$ & $38=27+9+(3-1)$ \\
\hline $9=9$ & $19=27-9+1$ & $29=27+(3-1)$ & $39=27+9+3$ \\
\hline $10=9+1$ & $20=27-(9+1)+3$ & $30=27+3$ & $40=27+9+3+1$ \\
\hline
\end{tabular}

Fonte: Os autores do artigo.

\footnotetext{
7 Q.E.D. significa "quod erat demonstrandum", uma expressão em latim cuja tradução é "como se queria demonstrar (c.q.d.)".
} 
Já o problema descrito no Quadro 9 está relacionado aos relógios presentes na sede da Sociedade Anti-Arteirítica, e quando esses irão badalar juntos novamente, pois os mesmos não trabalham na mesma sintonia.

\section{Quadro 9 - Problema dos três relógios}

Na sede da sociedade há três relógios. Só um vai certo. Os outros dois vão como muitas cabeças transtornadas: um adianta 10 minutos por dia, o outro atrasa 12 no mesmo tempo.

No $1^{\circ}$ de janeiro desse ano, ao meio dia em ponto, enquanto a sociedade se divertia com o "jogo do Chiquinho" os três relógios deram ao mesmo tempo 12 horas.

Quando os relógios calaram, Carlinhos se dirigiu a Chiquinho com mais esta:

"Se deixássemos correr os três relógios assim como andam, quando é que todos os três tornariam a dar às 12 horas ao mesmo tempo a três vozes"?

Quem dos pequenos satisfaz a pergunta?

Fonte: O Echo, 1920, v. 6, p. 229.

Para a resolução desse problema recreativo, inicialmente, pode-se utilizar a regra de três simples, observando o funcionamento dos dois relógios que não vão certo:

- O primeiro relógio adianta 10 minutos.

Como no dia primeiro do ano ele marcava 12 horas, quando esse fato irá ocorrer novamente ? Como 12 horas $=12 \mathrm{~h} \mathrm{x} 60 \mathrm{~min}=720$ minutos, tem-se:

1 dia ------ 10 minutos

$\mathrm{x}$ dias -------- 720 minutos

Portanto: $x=\frac{720}{10}=72$ dias esse fato irá acontecer novamente.

- O segundo relógio atrasa 12 minutos.

Então, como no dia primeiro do ano ele marcava 12 horas, esse fato irá acontecer novamente em:

1 dia --------- 12 minutos

$\mathrm{x}$ dias -------- 720 minutos

Logo: $x=\frac{720}{12}=60$ dias esse fato irá ocorrer novamente.

Porém, temos que determinar quando os três relógios irão tocar juntos, 12 horas novamente. A partir das informações é possível destacar que o mínimo múltiplo comum (m.m.c.) dos números 60 e 72 será o dia em que os relógios irão tocar juntos 12 horas novamente, conforme segue:

$$
\begin{aligned}
& M_{60}=\{0,60,120,180,240,300, \mathbf{3 6 0}, 420, \ldots\} \\
& M_{72}=\{0,72,144,216,288, \mathbf{3 6 0}, 432, \ldots\} \\
& \text { m.m.c. }(60,72)=\{360\}
\end{aligned}
$$

Portanto, os três relógios irão tocar juntos depois de 360 dias, ou seja, no dia 25 de dezembro desse mesmo ano.

No Quadro 10 se apresenta um problema recreativo que explora conhecimentos de análise combinatória, evidenciando permutações simples com elemento repetido. 
Quadro 10 - Problema de permutação com um elemento repetido

Olhem aí 4 papeizinhos, algarismos que formam juntos o número 9910. Quem me arruma a maior quantidade de números diferentes mudando a ordem dos papeizinhos, devendo cada número ter os quatro algarismos?

\begin{tabular}{c|c|c|c|}
\hline 9 & 9 & 1 & 0 \\
\hline
\end{tabular}

Para a resolução desse problema recreativo se utiliza permutação com repetição, pois se observa que o algarismo 9 repete uma vez. Ressalta-se que se não houvesse repetição seria a permutação dos quatro algarismos, ou seja, $\mathrm{P}=4 !=4 \cdot 3 \cdot 2 \cdot 1=24$ possibilidades. Como o algarismo 9 se repete, ocorre duas vezes, a expressão utilizada é a seguinte:

$\mathrm{P}=\frac{4 \text { ! }}{2 !}$, sendo 2 ! o número de vezes que o 9 ocorre.

Logo, $\mathrm{P}=\frac{24}{2}=12$ possibilid ades.

Além disso, como não existe número de 4 algarismos começando com o 0 (zero), esses devem ser descontados, ou seja, fixa-se o zero na primeira casa e o nove continua repetindo nas três seguintes: $0_{---}$. Logo, $\mathrm{P}=\frac{3 !}{2 !}=\frac{6}{2}=3$ possibilidades.

Finalizando, $\mathrm{P}=\frac{4 !}{2 !}-\frac{3 !}{2 !}=\frac{24}{2}-\frac{6}{2}=\frac{18}{2}=9$ possibilidades.

E os números obtidos são os seguintes: 1099, 1909, 1990, 9019, 9091, 9109, 9190, 9901 e 9910.

$\mathrm{Na}$ sequência se apresenta outro problema recreativo que exige conhecimentos de permutação com elementos repetidos, conforme descrito no Quadro 11:

Quadro 11 - Problema de permutação com dois elementos repetidos

E destes 5 algarismos quantos números de 5 algarismos se pode formar? \begin{tabular}{|l|l|l|l|l|}
\hline 8 & 0 & 8 & 0 & 8 \\
\hline
\end{tabular}

Fonte: O Echo, 1920, v. 7, p. 283.

No excerto descrito no Quadro 11, observa-se outro problema de permutação com repetição, pois o algarismo 0 (zero) se repete duas vezes, e o algarismo 8 se repete três vezes. Ressalta-se que se não houvesse repetição seria a permutação dos cinco algarismos, ou seja, P $=5 !=5 \cdot 4 \cdot 3 \cdot 2 \cdot 1=120$ possibilidades.

Como os algarismos 0 e 8 se repetem, tem-se:

$\mathrm{P}_{1}=\frac{5 !}{2 ! .3 !}=\frac{120}{2.6}=\frac{120}{12}=10$ possibilidades.

Ainda deve-se descontar as possibilidades que começam por 0 , isto é, $0_{-}{ }_{-}$: 
$\mathrm{P}_{2}=\frac{4 !}{3 !}$, sendo 3 ! o número de vezes que o 8 se repete.

$\mathrm{P}_{2}=\frac{24}{6}=4$ possibilidades.

Logo, $\mathrm{P}=\mathrm{P}_{1}-\mathrm{P}_{2}=10-4=6$ possibilid ades.

E os 6 números obtidos são os seguintes: 80088, 80808, 80880, 88008, 88080 e 88800.

O problema recreativo descrito no Quadro 12 desafia dois sócios da "Sociedade Antiarteirítica" sobre curiosidades numéricas envolvendo soma e produto de dois e três números, respectivamente.

\section{Quadro 12 - Problema da soma e produto de números}

Soma ou produto?

Norberto: Eu conheço dois números cuja soma é igual ao seu produto.

Carlinhos: Ora! Grande coisa! Pois eu sei três números cuja soma e produto também dão o mesmo.

Quem descobre os dois números de Norberto e os três números de Carlinhos?

Fonte: O Echo, 1920, v. 9, p. 355-356.

A solução do problema proposto no Quadro 12 revela os dois números de Norberto, que são 2 e 2 , pois $2+2=2$ x $2=4$. Já os três números referenciados por Carlinhos são 1,2 e 3 , pois $1+2+3=1 \times 2 \times 3=6$.

No Quadro 13 se apresenta outro problema recreativo que envolve pesos e suas possíveis combinações, utilizando-se somente de cinco pesos para pesar de 1 a 121 quilos.

\section{Quadro 13 - Problema dos pesos do compadre Juca}

Muito inchado andava o tio Pafuncio com a descoberta dos seus 4 pesos para os 40 quilos. Até pensava em tirar patente da invenção, quando lhe entra porta adentro o compadre Juca, que logo se sai com essa: "Olhe, seu compadre Pafuncio, anda! Não precisa estar com o papo muito cheio e assoprando pela novidade de sua invenção. Eu lá na minha loja das 'três botas' uso somente 5 pesos, apenas 1 mais que o compadre, e com eles lhe ponho em pratos limpos todos os quilos de 1 a 121 ". Quem quiser abrir armazém de atacado, mas com só poucos pesos, vai espreitar as manipulações do compadre Juca, e para a seguinte vez, venha nos dizer: Quanto pesa cada um dos 5 pesos? E como o compadre Juca põe em pratos limpos os quilos de 1 a 121 ?

Fonte: O Echo, 1920, v. 9, p. 356.

Inicialmente, aponta-se que os pesos apresentados pelo compadre Juca são de 1, 3, 9, 27 e 81 quilos, pois $1+3+9+27+81=121$ quilos. Trata-se de uma progressão geométrica (P.G.) de cinco termos em que o primeiro termo é igual 1, a razão é 3 e a soma desses cinco termos é 121. Esse problema pode ser resolvido de forma semelhante ao problema descrito no Quadro 7, sendo que os cinco pesos utilizados pelo compadre Juca para pesagens de 1 a 121 quilos constituem as possíveis combinações, utilizando-se somente esses pesos, conforme apresentado no Quadro 14: 


\begin{tabular}{|c|c|c|c|}
\hline \multicolumn{4}{|c|}{27 e $81 \mathrm{~kg}$} \\
\hline $1=1$ & $\ldots$ & $20=(27+3)-(9+1)$ & $112=81+27+3+1$ \\
\hline $2=3-1$ & $\ldots$ & $30=27+3$ & $113=81+27+9-(3+1)$ \\
\hline $3=3$ & $\ldots$ & $40=27+9+3+1$ & $114=81+27+9-3$ \\
\hline $4=3+1$ & $\ldots$ & $50=81-(27+3+1)$ & $115=81+27+9-(3-1)$ \\
\hline $5=9-(3+1)$ & $\ldots$ & $60=81-27+(9-3)$ & $116=81+27+9-1$ \\
\hline $6=9-3$ & $\ldots$ & $70=81-(9+3)+1$ & $117=81+27+9$ \\
\hline $7=(9+1)-3$ & $\ldots$ & $80=81-1$ & $118=81+27+9+1$ \\
\hline $8=9-1$ & $\ldots$ & $90=81+9$ & $119=81+27+9+(3-1)$ \\
\hline $9=9$ & $\ldots$ & $100=81+27-(9-1)$ & $120=81+27+9+3$ \\
\hline $10=9+1$ & $\ldots$ & $110=81+27+(3-1)$ & $121=81+27+9+3+1$ \\
\hline
\end{tabular}

Fonte: Os autores do artigo.

Outro problema para os pequenos mathemáticos é descrito no Quadro 15:

\section{Quadro 15 - Problema dos sete estudantes}

Conheci em tempos sete estudantes muito patuscos que até seus próprios nomes pareciam uma patuscada, pois respondiam a chamada esquisita de Mall, Mell, Mill, Moll, Mull, Nikles, Nokles. Todos frequentavam o café do dito compadre Pedro Penedo da Rocha Calhau. Mall aparecia todos os dias, Mell de dois em dois dias, Mill cada três dias, Moll cada quatro dias, Mull cada cinco dias, Nikles cada seis dias e Nokles só de sete em sete dias.

Certo dia se deu o caso raro de se encontrarem todos os sete reunidos, pelo que logo começou a patuscada, desta vez com o dono do café:

"Olhe seu Pedro Penedo da Rocha Calhau" - disseram - "nós somos os que os franceses chamam de habitues do teu café". Mall está todos os dias aqui, Mell cada dois dias, Mill cada três dias, Moll cada quatro dias, Mull cada cinco dias, Nikles cada seis dias e Nokles cada sete dias, quando pela segunda vez suceder que cá nos encontraremos todos, o Compadre nos dará um jantar de gala e, de graça. Valeu?

Valeu!! Respondeu o Compadre, certo de que nunca, enquanto ele fosse vivo, precisava pagar a patuscada dos estudantes.

Os pequenos matemáticos agora me digam, depois de quantos dias Mall, Mell, Mill, Moll, Mull, Nikles e Nokles tiveram um regabofe à custa do Compadre Pedro Penedo da Rocha Calhau?

Fonte: O Echo, 1920, v. 10, p. 401.

A partir das informações desse problema recreativo é possível destacar que se trata da decomposição dos números em fatores primos pelo processo de decomposição simultânea dos números 1, 2, 3, 4, 5, 6 e 7, conforme descrito na Figura 3:

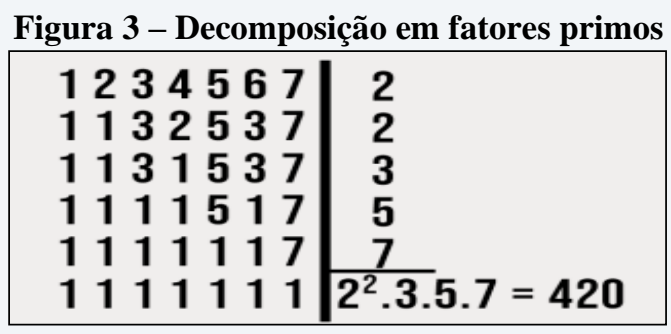

Fonte: Os autores do artigo.

Por meio da resolução mostrada na Figura 3, constata-se que o regabofe na casa de Pedro Penedo da Rocha Calhau se daria após 420 dias, que é o mínimo múltiplo comum dos números $1,2,3,4,5,6$ e 7 . 
No Quadro 16 se apresenta um problema recreativo que envolve conhecimentos lógicos e habilidades com números por meio de um quadrado mágico.

\section{Quadro 16 - Problema do número 13}

Aí tendes um retângulo de 8 pontos e 8 cartões com os números de 1 a 8 . Vede se me colocais os cartões sobre os pontos, assim que a soma dos três números de qualquer lado do retângulo sempre dêem o mesmo do caiporismo 13. Quem não é caipora, nem tem medo da mandinga do número 13, que experimente!

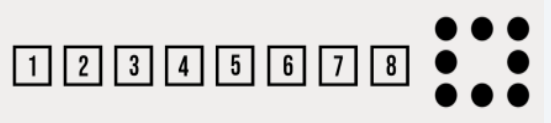

Fonte: O Echo, 1920, v. 11-12, p. 466.

$\mathrm{Na}$ Figura 4 se apresenta a solução do problema sugerido, para os diferentes lados do quadrilátero. Ressalta-se a necessidade de somar grupos com três números, a partir dos números de 1 a 8 , de forma que as somas dos lados devem sempre ser iguais a 13 .

Figura 4 - Solução do problema do número 13

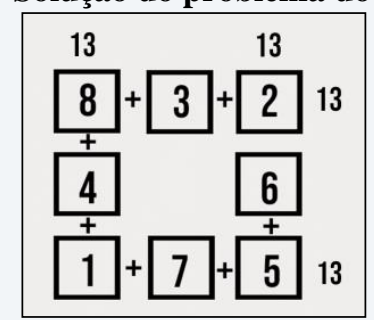

Fonte: Os autores do artigo.

$\mathrm{Na}$ sequência se apresenta um problema recreativo que exige interpretações numéricas, conforme descrito no Quadro 17:

\section{Quadro 17 - Problema da corrida de lesmas}

No tempo em que ainda falavam: Os animais como a gente... Duas lesmas se desafiavam para uma corrida. $\mathrm{O}$ alvo era subir em um muro de 20 pés de altura. As duas comadres lesmas chamaram ao compadre Caracol para que desse o sinal de partida. O compadre Caracol pôs uma dum lado do muro e a outra do outro, e deu o sinal. Um! Dois! Três! E lá se vão as duas comadres a todo o vapor de lesmas. Cada dia sobem 5 pés, mas durante o sono, cada noite, escorregam 4 pés para trás. Ambas são iguais em avançar, ambas iguais em retroceder. Pergunta: Depois de quantos dias as duas comadres descobrem o empate no alto do muro?

$$
\text { Fonte: O Echo, 1921, v. 1, p. } 25 .
$$

A partir das informações descritas no Quadro 17, ou seja, subir 5 pés durante o dia e escorregar 4 pés durante a noite, a resolução desse problema recreativo pode ser feita por meio das seguintes relações:

$$
\begin{array}{ll}
1^{\circ} \text { dia } \rightarrow 5-4=1 \text { pé. } & 2^{\circ} \text { dia } \rightarrow 1+5-4=2 \text { pés. } \\
3^{\circ} \text { dia } \rightarrow 2+5-4=3 \text { pés. } & 4^{\circ} \text { dia } \rightarrow 3+5-4=4 \text { pés. }
\end{array}
$$




$$
\begin{array}{ll}
5^{\circ} \text { dia } \rightarrow 4+5-4=5 \text { pés. } & 6^{\circ} \text { dia } \rightarrow 5+5-4=6 \text { pés. } \\
7^{\circ} \text { dia } \rightarrow 6+5-4=7 \text { pés. } & 8^{\circ} \text { dia } \rightarrow 7+5-4=8 \text { pés. } \\
9^{\circ} \text { dia } \rightarrow 8+5-4=9 \text { pés. } & 10^{\circ} \text { dia } \rightarrow 9+5-4=10 \text { pés. } \\
11^{\circ} \text { dia } \rightarrow 10+5-4=11 \text { pés. } & 12^{\circ} \text { dia } \rightarrow 11+5-4=12 \text { pés. } \\
13^{\circ} \text { dia } \rightarrow 12+5-4=13 \text { pés. } & 14^{\circ} \text { dia } \rightarrow 13+5-4=14 \text { pés. } \\
15^{\circ} \text { dia } \rightarrow 14+5-4=15 \text { pés. } & 16^{\circ} \text { dia } \rightarrow 15+5=20 \text { pés. }
\end{array}
$$

No $16^{\circ}$ dia, pela manhã estavam a 15 pés de altura, avançando mais 5 pés durante esse dia, à noitinha puderam atingir o topo do muro de 20 pés. Como ambas avançavam e retrocediam igualmente, obtiveram um empate, levando 16 dias para alcançar o objetivo.

O problema descrito no Quadro 18 apresenta outra curiosidade numérica, relacionada com os divisores de dois números, denominados por Chiquinho de "números curiosos".

\section{Quadro 18 - Problema dos números curiosos}

Curiosidade é droga muito espalhada por este mundo de Cristo! Meninos curiosos, meninas curiosas, até números curiosos há. De tais números Chiquinho conhece dois que são tão curiosos e capazes de excitar a curiosidade até dos pequenos mathemáticos menos curiosos. Olhem que são números tão curiosos que: "A soma de todos os divisores do $1^{\circ}$ dá o $2^{\circ}$ e a soma de todos os divisores do $2^{\circ}$ dá o $1^{\circ}$ número". Pergunta: Quem me diz os dois números curiosos? Olhem que ficam entre 200 e 300.

Fonte: O Echo, 1921, v. 1, p. 25.

Esses números curiosos procurados são 220 e 284, pois ao se considerar o conjunto dos divisores desses números, exceto eles mesmos, tem-se:

$-D_{220}=\{1,2,4,5,10,11,20,22,44,55,110\}$, cuja soma perfaz 284;

- $\mathrm{D}_{284}=\{1,2,4,71,142\}$, e somando esses divisores se encontra 220. Então, não são curiosos esses dois números?!

No Quadro 19, destaca-se outro problema recreativo envolvendo análise combinatória, de modo particular, conhecimentos de arranjos simples.

\section{Quadro 19 - Problema das 4 lanternas de furta-fogo}

Carlinhos recebeu do Tio Philatélico 4 lanternas de furta-fogo, todas de cor diferente. Desde então, em dias de chuva, diverte-se Carlinhos à noitinha em telegrafar ao primo Cebolico que mora lá para os Cafundós sobre uma colina. E coisa estranha! Carlinhos afirma que já forma várias dezenas de sinais, com as lanternas sempre só em linha horizontal. Será verdade?! Ou senão, digam-lá quantos sinais pode fornecer a "estação radiográfica" de Carlinhos.

Fonte: O Echo, 1921, v. 2, p. 67.

No excerto descrito no Quadro 19, observa-se um problema de arranjo simples, porque a ordem das cores das quatro lanternas transmitem sinais diferentes. Inicialmente, consideram-se as seguintes situações: 


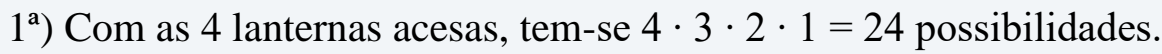

$2^{\text {a) }}$ Com 3 lanternas acessas, existem $4 \cdot 3 \cdot 2=24$ possibilidades.

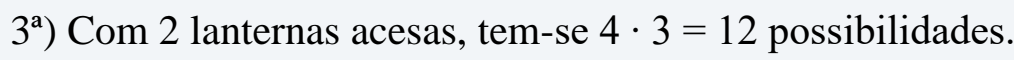

$4^{\mathrm{a}}$ ) Com só 1 lanterna acesa, existem somente 4 possibilidades.

Somando os valores encontrados nas quatro situações, chega-se ao total de sinais possíveis na estação "radiográfica de Carlinhos", isto é, $24+24+12+4=64$ possibilidades.

No Quadro 20 se apresenta outro problema recreativo com denominação de "jogo dos 6", ontre trabalha-se permutação simples, conforme segue:

Quadro 20 - Problema do jogo dos 6

Certo dia, Mall, Mell, Mill, Moll, Mull, Nikles e Nokles tiveram um regabofo à custa do "Café Familiar". Nokles, o mais patusca dos 7 estudantes, para engarapar o compadre fez não sei se proposta, se patifaria... Rapidamente explicara seu plano aos 6 companheiros e só então saiu-se ao engodo. Levantou-se e pôs-se ao lado do Compadre e puxando da carteira uma nota de 500\$000 disse decidido:

- "Senhor Compadre Pedro Penedo da Rocha Calhau, estes $500 \$ 000$ agora mesmo são seus se o Senhor nos der tantos dias café de graça quantas vezes esses meus 6 companheiros pôrse a mesa em ordem trocada. Os gastos de cada dia seja para o Senhor apenas de 10 tostões por café! Aceita?!"

Pedro Penedo aceitou e no dia seguinte o malandro do Nokles começou com seu cafezinho de 10 tostões enquanto dos 6 companheiros sempre 1 só todos os dias mudava de lugar.

Perguntas: $1^{\text {a }}$ ) Quantos dias pode durar este jogo dos 6?

$2^{a}$ ) Quem saiu logrado, Nokles ou o Compadre Pedro Penedo da Rocha Calhau? Fonte: O Echo, 1921, v. 2, p. 68.

Para a resolução desse problema recreativo se utiliza uma permutação simples. Ressalta-se que não houve repetição, logo, trata-se de uma permutação de 6 . A resolução do problema consiste numa permutação dos 6 companheiros na mesa do "Café Familiar", ou seja, $\mathrm{P}_{6}=6 !=6 \cdot 5 \cdot 4 \cdot 3 \cdot 2 \cdot 1=720$ posições diferentes. Portanto, houve 720 cafés, por aproximadamente 2 anos. E o Compadre Pedro Penedo da Rocha Calhau foi logrado com cerca de $220 \$$, pois as despesas com o café totalizam $720 \$$ e foram antecipados $500 \$$, faltando ainda $220 \$$.

O problema recreativo descrito no Quadro 21 desafia o pequeno mathemático Carlinhos a proteger a praça com 300 soldados. Neste, observam-se as estratégias utilizadas para mater a praça afastada da invasão dos inimigos. 


\section{Quadro 21 - Problema da praça forte de Carlinhos}

Nem todas as artes são, mas, só não prestam as artes de arteiros. Aqui verá um exemplo, que nada tem de arteiro, mas muito de arte. Carlinhos é oficial militar. Em manobras recebeu ordem de, com só 300 soldados, defender uma praça forte guarnecendo cada lado da praça com o maior número de soldados.

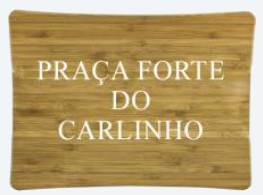

O inimigo, quando pela manhã mandou o primeiro espião, soube que a fortaleza estava defendida por 100 soldados de cada lado. À noite, um segundo espião trouxe a notícia de que 125 soldados guarneciam cada lado do quadrilátero. No dia seguinte, quando deveria ser o assalto, um terceiro espião informou. "É impossível o ataque: nada menos do que 150 soldados protegem cada um dos quatro lados!

Em consequência do grande número de defensores, o inimigo não ousou acometer. Retirouse. E Carlinhos, sem cheirar sequer pólvora tinha defendido a praça, só com sua arte militar. Pergunta: Como pode o esperto militar, com só 300 soldados meter, 100, 125 e até 150 em cada um dos 4 lados, se 4 × $100=400$, e 4 × $125=500$ e 4 × $150=600$ ?

Fonte: O Echo, 1921, v. 5, p. 187.

A estratégia de defesa utilizada por Carlinhos para distribuir os 300 soldados consistiu em, pela manhã, um dia antes do ataque, distribuir 25 soldados em cada canto da praça, sendo os demais 50, distribuídos pelo entorno, totalizado 100 soldados em cada lado. À noite, o oficial militar reforçou os cantos com 50 soldados, e os demais pelo entorno da praça, 25, totalizando 125 soldados em cada lado. Finalmente, no dia do ataque, Carlinhos concentrou todo o efetivo nos quatro cantos da praça, com 75 soldados em cada um. Com isso, o militar, com o mesmo número de 300 soldados, confundiu o inimigo, aumentando o efetivo nos pontos de ataque. A Figura 5 ilustra a estratégia utilizada por Carlinhos para proteger a praça:

Figura 5 - Distribuição dos 300 soldados na praça

\begin{tabular}{|c|c|c|c|c|c|c|}
\hline $\begin{array}{c}25 \\
+\end{array}$ & 50 & & $\underset{+}{50+25+50}$ & & + & 75 \\
\hline 50 & 300 & 50 & 25300 & + & 300 & + \\
\hline+ & & + & + & $\|$ & & $\|$ \\
\hline $25^{+}$ & 50 & +25 & $\underset{\|}{50}+25+50$ & 150 & & 150 \\
\hline 100 & & 100 & 125 & & & \\
\hline
\end{tabular}

Fonte: O Echo, 1921, v. 7, p. 266.

No Quadro 22 se apresenta um problema recreativo envolvendo três quadros com os números 4,8 e 9. Após riscar a metade deles, deve-se obter a soma 100. 
Quadro 22 - Problema da soma 100

Rudi: - Arre! Isto também já é exigir muito! Quer o Chiquinho que eu risque destes 36 algarismos a metade, isto é 18; e isto assim que a soma dos que ficam perfaça exatamente 100 , devendo ficar alguns 4 , alguns 8 e alguns 9 . Não me acerto com os números.

\begin{tabular}{|c|c|c|c|c|c|}
\hline \multirow{5}{*}{\multicolumn{2}{|c|}{$\begin{array}{l}4 \\
4 \\
4 \\
4 \\
4\end{array}$}} & & 4 & & 4 \\
\hline & & 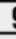 & 9 & & 4 \\
\hline & 9 & 8 & 8 & 9 & 4 \\
\hline & 9 & 8 & 8 & 9 & 4 \\
\hline & & & 9 & & 4 \\
\hline & & & & & 4 \\
\hline
\end{tabular}

Norberto: "Chi! Rudi! Vergonha! Queres ser matemático e não atinas com esse brinquedinho facílimo! Vê como se faz!"

E Norberto riscou às pressas 18 algarismos, mas com espírito tão justiceiro e certeiro que saíram fora: alguns dos 4, dos 8 e dos 9; ficando também no quadro: alguns dos 4, dos 8 e dos 9. Rudi fez a soma dos 18 que ficaram e deu mesmo 100! Quem dos pequenos for tão esperto como o Norberto, mande-me o quadro com os 18 que ficaram.

Fonte: O Echo, 1924, v. 4, p. 124.

Em duas edições posteriores da revista $O$ Echo de 1924, é apresentada uma solução para esse problema recreativo, somente com o emprego de conhecimentos de aritmética, eliminando-se os 18 números, para obter a soma 100. Observa-se, de forma curiosa, que o quadro apresenta variada simetria, conforme mostrado na Figura 6:

Figura 6 - Solução do problema da soma 100

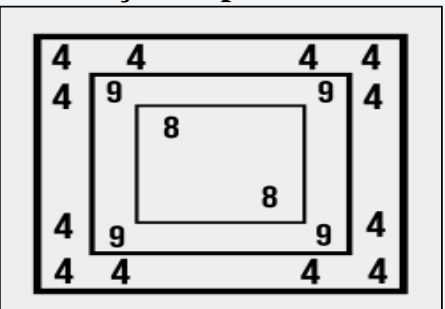

Fonte: O Echo, 1924, v. 6, p. 190.

O último problema recreativo apresentado neste artigo, e descrito no Quadro 23, pode ser resolvido de forma semelhante ao problema da praça de Carlinhos.

Quadro 23 - Problema do sumiço dos pacotes de bolachas

Desta vez não é chiquinhada, não; é sim uma Zé-Pinhice. Seu Androlico do Cerro e Dona Maricota da Serra tinham 4 filhos. "Mimosos" chamavam-nos os pais fazendo-lhes todas as vontades, "malcriados e arteiros", diziam os vizinhos talvez com mais acertos. Eram de gênio tal, que só se endireita à força de energia; e energia faltava a Dona Maricota e mais a seu Androlico. Assim, era fácil prever que os 4 pimpolhos iam caminhar cada vez mais pela vereda dos "malcriados e desordeiros", que tais seriam sempre chamados "mimosos", que se pervertem pela demasiada condescendência dos pais.

Certo dia, Dona Maricota recebeu de presente 40 pacotinhos de bolachas das mais finas e doces. Só faltavam 5 dias para os anos de seu Androlico, e as bolachas deveriam ficar para o dia da festa do pai. A mãe, é verdade, desconfiava um tanto dos seus 4 "mimosos", pois se as escondidas surrupiassem alguns pacotinhos não seriam o primeiro exercício na arte de furtar. Era preciso 
fiscalizar; o que Dona Maricota fez do modo mais tolo possível. Se ela era boba em educar os "mimosos", eram mais espertos em abusar. Na despensa havia um armário alto, acessível dos 4 lados. Para mais fácil contagem, Dona Maricota pôs os pacotinhos sobre o armário formando 3 grupos para cada lado do armário, contando-se 11 pacotinhos de cada um dos 4 lados. Já se vê como era grande a desconfiança da mãe; mas ainda maior era a gula dos filhos, e maior ainda a esperteza dos mesmos. Já na tarde do $1^{\circ}$ dia, cada um dos 4 tinha tirado um pacote e, contudo, a mãe via para cada banda 3 grupos de 11 pacotinhos. No segundo dia, mais 4 pacotes desapareceram, e a mãe sempre a contar 3 grupos de 11 pacotinhos. Com o $3^{\circ}$ dia, outros 4 tinham levado sumiço e com o $4^{\circ}$ dia, novos 4, e a mãe a repetir sem alteração: três grupos e 11 pacotinhos. Só no $5^{\circ}$ dia, Dona Maricota caiu na conta do roubo, ainda contava os 11 pacotinhos, mas havia só dois grupos para cada lado. Ao examinar melhor o armário, o que ela havia de descobrir! - Nada menos que 18 pacotinhos tinham levado sumiço no bojo insaciável na barriga dos 4 "mimosos", arteiros, gulosos e ladrões. Não sei da emenda que os 4 levaram na ocasião, nem sei se continuaram "mimosos", mas sei que se fossem filhos de meu pai nunca se teriam aventurado na tal Zé-Pinhice ou, pelo menos, logo a seguir teriam visto estrelas ao meio dia e de quantas taboas se faz uma canoa. E agora, meus pequenos mathemáticos, transformemos essa Zé-Pinhice em Chiquinhadas:

$1^{\circ}$ ) Como fizeram os 4 para sempre haver em cada lado 3 grupos e 11 pacotes nos 4 dias sucessivos?

$2^{\circ}$ ) Qual foi à disposição no $5^{\circ}$ dia, dia da fatal descoberta?

Fonte: O Echo, 1924, v. 8, p. 254.

Considerando-se as informações desse problema recreativo é possível descrever a disposição dos pacotinhos de bolachas realocados pelos "mimosos" durante os 5 dias, até a mãe descobrir o sumiço de 18 pacotinhos de bolachas. A Figura 7 mostra essa distribuição dos pacotinhos durante os 5 dias:

Figura 7 - Distribuição dos pacotinhos durante os 5 dias

\begin{tabular}{|c|c|c|c|c|}
\hline $\begin{array}{lr}2-7-2 \\
1 & 7 \\
7 & 7 \\
1 & 1 \\
2 & -7-2 \\
1 & \\
1 & \text { DIA }\end{array}$ & $\begin{array}{rr}3-5 & -3 \\
1 & 1 \\
5 & 5 \\
1 & 1 \\
3 & -5-3 \\
2 & \\
2 & \text { DIA }\end{array}$ & $\begin{array}{rr}4-3 & -4 \\
1 & 3 \\
3 & 3 \\
1 & -3-4 \\
3 & \text { DIA }\end{array}$ & $\begin{array}{rr}5-1 & -5 \\
1 & 1 \\
1 & 1 \\
5 & -1 \\
5 & -5 \\
4^{\circ} & \text { DIA }\end{array}$ & 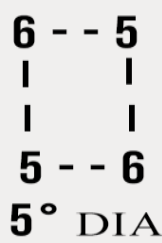 \\
\hline
\end{tabular}

Fonte: O Echo, 1924, v. 11-12, p. 364.

As artimanhas dessa "Zé-Pinhice" consistiram em retirar dois pacotinhos de cada lado do armário, acrescentando um pacotinho em cada canto, mantendo-se $11 \mathrm{em}$ cada lado do armário e distribuídos em três grupos. Já os quatro pacotinhos restantes, os "mimosos" afanavam, repetindo-se isso nos quatro primeiros dias, sem que a mãe desconfiasse de tal estratégia. Somente no quinto dia, ao retirarem dois pacotinhos, a mãe descobriu o roubo. Continuavam os 11 pacotinhos em cada lado do armário, porém, distribuídos somente em dois grupos. E assim, ao fazer a contagem dos pacotinhos, a mãe deu falta de 18 pacotinhos $(4+4$ $+4+4+2=18)$.

Vale ressaltar que a seção "Para Pequenos Mathemáticos" se fez presente em 31 edições da revista $O E c h o$, nos anos de 1919, 1920, 1921 e 1924, não aparecendo nos anos de 1922 e de 1923 e nas edições posteriores a 1924, por razão desconhecida. 


\section{Considerações finais}

A partir do referencial da história cultural, investigou-se a revista ilustrada $O$ Echo, com ênfase para os problemas recreativos presentes na seção "Para Pequenos Mathemáticos", nos anos de 1919, 1920, 1921 e 1924. O público-alvo da revista era a comunidade escolar e a mocidade católica brasileira, pois, segundo os editores, havia revistas para os diferentes públicos na época, exceto para os jovens estudantes. A ideia consistia em inserir algo que contemplasse todas as vozes, do sábio, narrador, colega jovial, historiador, jornalista, religioso, tudo isso para a vida da mocidade estudiosa, por meio de textos, histórias, informações e curiosidades, enfatizando os aspectos morais, religiosos e a formação em geral.

Nos artigos escritos na revista Echo são apresentados poemas, notícias, reflexões de padres e professores, conferências, variedades, anedotas, contos, publicações de premiações de alunos por redação ou por competição esportiva, anúncios de propagandas, ciências, invenções, artes, matemática, astronomia, reforma da língua portuguesa, descobertas, sendo que, após 1950, começam a aparecer artigos direcionados à prática esportiva, como futebol, bola ao cesto, entre outros. Nesses artigos, também há ilustrações, como fotografias de colégios, imagens de papas, padres, alunos, ex-alunos, personagens da história do Brasil, santos da Igreja Católica, paisagens, ilustrações de textos, cenários de guerra, futebol e humor.

Na seção "Para Pequenos Mathemáticos", encontraram-se 63 problemas recreativos. Esses problemas estão relacionados, principalmente, com conhecimentos de aritmética, álgebra e geometria. Com relação aos problemas recreativos envolvendo conhecimentos de aritmética se observaram operações fundamentais, critérios de divisibilidade, progressões, permutações e arranjos simples, evidenciando o raciocínio lógico e charadas. Dessa forma, os editores da revista $O$ Echo buscavam despertar o interesse e a curiosidade da mocidade estudiosa, contribuindo para a circulação da revista e a formação da juventude católica nos colégios onde a mesma circulava.

O estudo dos problemas recreativos na seção "Para Pequenos Mathemáticos", da revista $O$ Echo, permitiu investigar uma cultura escolar, num lugar e num tempo determinados, contribuindo, assim, para a História da Educação Matemática e o ensino de Matemática na Educação Básica. Isso, pois além de fontes históricas, possibilitam que professores se apropriem e levem às salas de aulas tais problemas para debate, sejam essas salas da escola ou até mesmo da universidade. Por fim, pondera-se que o objetivo foi 
alcançado e que a pesquisa terá sua continuidade com a investigação dos problemas recreativos envolvendo conhecimentos de álgebra e de geometria.

\section{REFERÊNCIAS}

BRITTO, Silvio Luiz Martins. O ensino da aritmética nas escolas paroquiais católicas e no Ginásio Conceição, sob a ótica dos jesuítas nos séculos XIX e XX. 2016. 464 f. Tese (Doutorado em Ensino de Ciências e Matemática) - Universidade Luterana do Brasil, Canoas, 2016.

BRITTO, Silvio Luiz Martins; BAYER, Arno; KUHN, Malcus Cassiano Kuhn. A contribuição dos jesuítas para o ensino da Matemática no Rio Grande do Sul. São Leopoldo, RS: Ed. UNISINOS, 2020.

CHARTIER, Roger. A História Cultural: entre práticas e representações. Lisboa: Difel, 1990.

KUHN, Malcus Cassiano. $O$ ensino da matemática nas escolas evangélicas luteranas do Rio Grande do Sul durante a primeira metade do século XX. 2015. 466 f. Tese (Doutorado em Ensino de Ciências e Matemática) - Universidade Luterana do Brasil, Canoas, 2015.

KUHN, Malcus Cassiano; BAYER, Arno. A matemática nas escolas paroquiais luteranas gaúchas do século XX. Canoas: Ed. ULBRA, 2017.

LEITE, Luiz Osvaldo. A revista O ECHO e sua trajetória. Porto Alegre/RS, 16 mar. 2018. Estágio Pós-doutoral em Programa de Pós-Graduação. Entrevista concedida a XXX.

O ECHO: revista ilustrada para a mocidade estudiosa. Typographia do Centro: Porto Alegre, 1914-1931.

O ECO: revista ilustrada para a mocidade brasileira. Tipografia do Centro: Porto Alegre, 1932-1969.

\section{RELATÓRIO DO COLÉGIO ANCHIETA. Porto Alegre, 1914. p. 28.}

SERRA, Áurea Esteves. As associações de alunos das escolas normais do Brasil e de Portugal: apropriação e representação (1906-1927). 2010. 290 f. Tese (Doutorado em Educação) - Universidade Estadual Paulista, Marília, 2010.

SPOHR, Inácio. Memórias dos 665 Jesuítas da Província do Brasil Meridional. Novembro de 1867 - novembro de 2011. Porto Alegre: Livraria e Editora Padre Reus, 2011.

VALENTE, Wagner Rodrigues. História da Educação Matemática: interrogações metodológicas. REVEMAT - Revista Eletrônica de Educação Matemática, UFSC, v. 2.2, p. 28-49, 2007. 
WEIDUSCHADT, Patrícia. A revista "O Pequeno Luterano" e a formação educativa religiosa luterana no contexto pomerano em Pelotas - RS (1931-1966). 2012. 273 f. Tese (Doutorado em Educação) - Universidade do Vale do Rio dos Sinos, São Leopoldo, 2012.

\section{$\underline{\text { SOBRE OS AUTORES }}$}

\section{Silvio Luiz Martins Britto}

Doutor em Ensino de Ciências e Matemática pela Universidade Luterana do Brasil ULBRA/Canoas/RS/Brasil. Pós-doutorando no Programa de Pós-Graduação em Ensino de Ciências e Matemática - PPGECIM - da Universidade Luterana do Brasil ULBRA/Canoas/RS/Brasil. Professor das Faculdades Integradas de Taquara FACCAT/Taquara/RS/Brasil. Membro do Grupo de Pesquisas sobre Formação de Professores de Matemática - GPFPMat. E-mail: silviobritto@ faccat.br

\section{http://orcid.org/0000-0001-5222-0126}

\section{Malcus Cassiano Kuhn}

Doutor em Ensino de Ciências e Matemática pela Universidade Luterana do Brasil ULBRA/Canoas/RS/Brasil. Estágio Pós-doutoral no Programa de Pós-Graduação em Ensino de Ciências e Matemática - PPGECIM, na Universidade Luterana do Brasil ULBRA/Canoas/RS/Brasil. Professor do Ensino Básico, Técnico e Tecnológico no Instituto Federal de Educação, Ciência e Tecnologia Sul-rio-grandense - IFSul Câmpus Lajeado/RS/Brasil. Chefe do Departamento de Ensino, Pesquisa e Extensão do Instituto Federal de Educação, Ciência e Tecnologia Sul-rio-grandense - IFSul Câmpus Lajeado/RS.

Coordenador do Polo UAB do IFSul Câmpus Lajeado/RS/Brasil. Membro da Câmara de Ensino do IFSul. Membro titular da Câmara de Pesquisa, Inovação e Pós-graduação do IFSul, representando a grande área de Ciências Exatas e da Terra. Membro titular do Conselho Editorial da Editora IFSul. Membro do Grupo de Pesquisas sobre Formação de Professores de Matemática - GPFPMat. Líder do Grupo de Pesquisa Estratégias de Ensino para Educação Básica e Profissional. E-mail: malcuskuhn@ifsul.edu.br

(iD http://orcid.org/0000-0002-6001-2324

\section{Arno Bayer}

Doutor em Ciências da Educação pela Universidade Pontifícia de Salamanca - Espanha. Professor e Pesquisador do Programa de Pós-Graduação em Ensino de Ciências e Matemática - PPGECIM da ULBRA/Canoas/RS/Brasil. Líder do Grupo de Pesquisas sobre Formação de Professores de Matemática - GPFPMat. E-mail: bayer@ulbra.br

iD http://orcid.org/0000-0001-7721-1162

Recebido em: 22 de fevereiro de 2020. Aprovado em: 04 de agosto de 2020

Publicado em: 01 de outubro de 2020 